\title{
Molecular Simulation of Polyimide Structure and Gas Permeation Properties
}

\author{
Kenji Matsumoto, Yoshihiro Minamizaki, and Ping $\mathrm{Xu}$
}

Central Research Laboratory, Nitto Denko Corporation 1-1-2, Shimohozumi, Ibaraki, Osaka, 567, JAPAN

Polyimide membranes of 6 FDA-p- PDA, 6 FDA-4, 4'-ODA and BTC-4, 4'-ODA were prepared. Gas permeabilities and selectivities of carbon dioxide and methane for the films were measured. 6 FDA polyimides exhibit both high selectivities and high permeabilities in $\mathrm{CO}_{2} / \mathrm{CH}_{4}$ separation. Molecular structure of polyimides were investigated by using molecular simulation technique. 6FDA polyimides show helix configuration due to bending and twisting of polymer chain at carbon atom having $-\mathrm{C}\left(\mathrm{CF}_{3}\right)_{2}$ - substituent groups. On the other hand normal polyimides without $-\mathrm{C}\left(\mathrm{CF}_{3}\right)_{2}-$ give straight configuration. Helix configuration can be one of the important reason for high selectivity and high permeability of hexafluoro-substituted polyimide.

Key words : Separation membrane, Gas permeation, Polyimide structure, Fluorine, Molecular simulation

\section{INTRODUCTION}

Within the last decade a number of gas separation membrane systems have been studied and introduced commercially. Especially $\mathrm{CO}_{2} / \mathrm{CH}_{4}$ separation membrane is being actively developed. Lowgrade natural gas can be purified by the removal of carbon dioxide. Carbon dioxide can then be reused in tertiary oil recovery. Recently, it is reported that polyimides with 2,2-bis (3,4-decarboxyphenyl) hexafluoropropane dianhydride (6 FDA) exhibit both a higher gas selectivity and permeability than general polyimides and common polymers ${ }^{1,2)}$. Therefore a number of studies on the relationship between the chemical structures of the polyimides and their gas permeation and separation properties have been done ${ }^{3 \sim 11)}$.

In order to develop good membrane materials, it is essential to investigate systematically the relationship between chemical and physical structures of the polymers and their permeabilities to gases. In most cases, increases in permeability are attended by losses in permselectivity. But 6 FDA polyimide was found to be improved for $\mathrm{CO}_{2} / \mathrm{CH}_{4}$ separation in both permeabilities and permselectivities. This is explained intrasegmental mobility, intersegmental packing of membrane polymers and fractional free volume. But polymer structure is so complicated that the mechanism of gas permeation is not well understood.

Recently computer simulation of polymer structure is developed by using molecular dynamics calculation $^{12 \sim 14)}$. From this simulation, we can get polymer structure information and discuss the difference of gas permeation mechanism.

In the present work, three types of polyimide were synthesized and physical properties and permeabilities of $\mathrm{CO}_{2}$ and $\mathrm{CH}_{4}$ were measured and polymer structures were investigated using computer graphic and molecular dynamic simulation calculation. 
<smiles></smiles>

6FDA-p-PDA

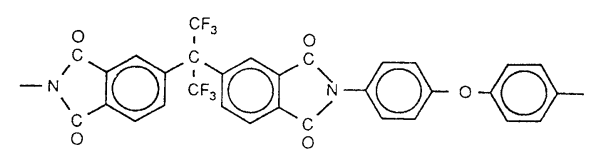

6FDA-4,4'-ODA

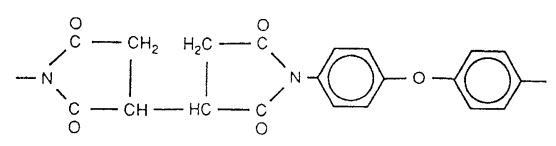

BTC-4, 4'-ODA

Fig. 1. Chemical structure of polyimides used in this study.

\section{EXPERIMENTAL}

The chemical structures of the polyimides used in this study are shown in Fig. 1. The polymerization reaction was performed by solution condensation polymerization method at room temperature under the nitrogen atmosphere ${ }^{10)}$. The 6 FDA dianhydride monomer $(0.2 \mathrm{~mol})$ was added to aromatic diamine $(0.2 \mathrm{~mol})$ such as Oxydianiline (ODA) and paraphenylenediamine (p-PDA) dissolved in $N$-methyl-2-pyrrolidone (NMP) to give precursor polyamic acids. For chemical imidization, acetic anhydride was added to 4 times equimolal amount of aromatic diamine as dehydrating agent and pyridine was added as catalyst. Polyamic acid solution were diluted to less than $10 \%$ to prevent gellation.

An aliphatic polyimide from 1,2,3,4-butane tetracarbonic dianhydride BTC-4,4'-ODA was also obtained by the same method for comparison.

The homogeneous films were prepared by casting the NMP solution of the polyimides on clean glass plates with an applicator, and dried in an oven at $100^{\circ} \mathrm{C}$ and $150^{\circ} \mathrm{C}$ for 5 hours respectively, and at $250^{\circ} \mathrm{C}$ for 3 hours. Thicknesses of the films were $15 \sim 35 \mu \mathrm{m}$.
Chemical structure of polymer synthesized was characterized by means of nuclear magnetic resonance (NMR) (JNM-GX 400, JEOL LTD., JAPAN). Glass transition temperatures $\mathrm{T}_{g}$ of film were determined by differential scanning calorimetry (DSC) (DSC 100, SEIKO Electronic Industry K.K., JAPAN). Average interchain spacing 'd'spacing was obtained from wide-angle X-ray diffraction (WAXD) (RU-200B, RIGAKU CO., LTD., JAPAN) measurements for the film. The inherent viscosity $\eta$ was obtained by measuring the viscosity of polyimide solution of $0.5 \mathrm{~g} / \mathrm{d} l$ in NMP at $30^{\circ} \mathrm{C}$. The density of film at $25^{\circ} \mathrm{C}$ was obtained by means of an accurate balance measuring specific gravity of the film in air and in water by using following equation.

$$
\mathrm{r}=\mathrm{W}_{A}\left(\mathrm{r}_{W}-\mathrm{r}_{A}\right) /\left(\mathrm{W}_{A}-\mathrm{W}_{W}\right)+\mathrm{r}_{A}
$$

where $\mathrm{W}_{A}, \mathrm{~W}_{W}$ are polymer weight in Air and Water, $r_{W}, r_{A}$ are polymer density in Air and Water.

Steady-state gas permeation measurements were carried out by use of pressure transform method at $25^{\circ} \mathrm{C}$ at $5 \mathrm{~atm}$. Permeation rates of carbon dioxide and methane in the films were determined using an Baratron pressure transducer and digital equipment with personal computer. The downstream pressure of membrane was always 10 torr or less.

Steric structure of the various polymers were estimated using molecular simulation technique. Geometry optimization of Monomer unit with diamine part and dianhydride part were calculated at first, then monomer unit was added one by one to reach around 20 units and each minimum energy was calculated. Calculations were carried out using POLYGRAF ver. 2.20 (BIODESIGN Inc.) on TITAN 750 computer workstation. (Kubota Computer Inc.) As a force field, DREIDING II ${ }^{15}$ ) was applied. In this force field, the potential energy for an arbitrary geometry of a molecule is expressed as a superposition of bonded and nonbonded interactions. 


$$
\begin{aligned}
& \mathrm{E}=\mathrm{E}_{b}+\mathrm{E}_{q}+\mathrm{E}_{f}+\mathrm{E}_{i}+ \\
& \text { bonded } \\
& \mathrm{E}_{v d w}+\mathrm{E}_{e l}+\mathrm{E}_{h b}
\end{aligned}
$$

nonbonded

The bonded interactions consist of bond stretching $\left(\mathrm{E}_{b}\right)$, bond angle bending $\left(\mathrm{E}_{q}\right)$, dihedral angle torsion $\left(\mathrm{E}_{f}\right)$, and inversion $\left(\mathrm{E}_{i}\right)$ terms, while the nonbonded interactions consist of van der Waals $\left(\mathrm{E}_{v d w}\right)$, electrostatics $\left(\mathrm{E}_{e l}\right)$, and hydrogen bond $\left(\mathrm{E}_{h b}\right)$ terms.

The bond stretching and bond angle bending are described as harmonic types

$$
\begin{aligned}
& \mathrm{E}_{b}=1 / 2 \mathrm{~K}_{b}\left(\mathrm{R}-\mathrm{R}_{0}\right)^{2} \\
& \mathrm{E}_{q}=1 / 3 \mathrm{~K}_{q}\left(\mathrm{q}-\mathrm{q}_{0}\right)^{2}
\end{aligned}
$$

where $\mathrm{K}_{b}$ and $\mathrm{K}_{q}$ are force constant. Equilibrium bond length between two atoms and angle among three atoms are represented by $R_{0}$ and $q_{0}$ respectively.

Dihedral Angle torsion is restricted by a potential of the form

$$
\mathrm{E}_{f}=\sum_{n=1}^{6} 1 / 2 \mathrm{~K}_{q, n}[1-\mathrm{d} \cos (\mathrm{nf})]
$$

where $f$ is a dihedral angle between two planes on which 4 atoms are included. $\mathrm{K}_{q, n}$ is a force constant, $d$ is \pm 1 phase factor.

Inversions is given

$$
\mathrm{E}_{i}=1 / 2 \mathrm{C}\left(\cos \mathrm{w}-\cos \mathrm{w}_{0}\right)^{2}
$$

where $\mathrm{C}$ is a force constant, $\mathrm{w}$ is a out-of-plane angle and $\mathrm{w}_{0}$ is a stable out-of-plane angle (constant).

van der Wasls interactions are given by LennardJones $12-6$ potential

$$
\mathrm{E}_{v d w}(\mathrm{R})=\mathrm{D}_{0}\left[\left(\mathrm{R}_{0} / \mathrm{R}\right) 12-2\left(\mathrm{R}_{0} / \mathrm{R}\right)^{6}\right]
$$

where $R$ is the distance between two atoms, $R_{0}$ is the van der Waals bond length, $D_{0}$ is the van der Waals well depth.

Electrostatic interactions are given

$$
\mathrm{E}_{e l}=(322.0637) \mathrm{Q}_{i} \mathrm{Q}_{j} / \mathrm{e} \mathrm{R}_{i j}
$$

where $Q_{i}$ and $Q_{j}$ are charges, $R_{i j}$ is the distance and $\mathrm{e}$ is the dielectric constant.

Hydrogen bond are given by Lennard-Jones 1210 type potential

$$
\begin{aligned}
\mathrm{E}_{h b}= & \left.\mathrm{D}_{h b}\left[5\left(\mathrm{R}_{h b} / \mathrm{R}_{D A}\right)^{12}-6 \mathrm{R}_{h b} / \mathrm{R}_{D A}\right)^{10}\right] \\
& \cos 4\left(\mathrm{q}_{D H A}\right)
\end{aligned}
$$

where $D_{h b}$ is the hydrogen bond strength (constant), $R_{h b}$ is the stable distance between the hydrogen acceptor (A) and the hydrogen donor (D) (constant), $\mathrm{R}_{D A}$ is the distance between the donor and acceptor atoms, while $\mathrm{q}_{D H A}$ is the bond angle among the donor, the hydrogen $(\mathrm{H})$, and the acceptor.

Nonbonded interactions are not calculated between atoms bonded to each other or atoms involved in angle interactions, since these are assumed to be included in the bond and angle interactions. To reduce the computational requirement, nonbonded interactions for pairs of atoms which are at a distance of more than $9 \AA$ are not calculated. The method used to minimige the potential energys was Conjugate Gradient.

\section{RESULTS AND DISCUSSION}

Physical properties of polyimides obtained in this experiment are summarized in Table 1.

Ideal separation factor $\alpha \mathrm{CO}_{2} / \mathrm{CH}_{4} \quad\left(=\mathrm{PCO}_{2} /\right.$ $\mathrm{PCH}_{4}$ ) as a function of $\mathrm{CO}_{2}$ mean permeability coefficient $\mathrm{PCO}_{2}$ are plotted in Fig. 2 for the polyimides obtained from the present work and commercial polymers from the literature ${ }^{1,2)}$. As shown in Fig. 2, 6FDA-p-PDA and 6FDA 4,4'-ODA exhibit exceptionally better permeability and selectivity than polyimide without $6 \mathrm{FDA}$ and commercial polymers. The $d$-spacing is a measure of intersegmental distance of polymeric molecules ${ }^{1,2)}$. Densities and $d$-spacing related to packing situa- 
Table 1 Physical properties of the polyimides prepared in this study

\begin{tabular}{c|c|c|c|c|c}
\hline No. & Polymer & $\begin{array}{c}n \\
{[\mathrm{~d} l / \mathrm{g}]}\end{array}$ & $\begin{array}{c}\rho \\
{\left[\mathrm{g} / \mathrm{cm}^{3}\right]}\end{array}$ & $\begin{array}{c}\mathrm{T}_{g} \\
{\left[{ }^{\circ} \mathrm{C}\right]}\end{array}$ & $\begin{array}{c}\mathrm{d} \\
{[\AA]}\end{array}$ \\
\hline A & 6FDA-p-PDA & 0.815 & 1.45 & 338 & 5.63 \\
\hline B & 6FDA-4, 4'-ODA & 2.37 & 1.43 & 297 & 5.88 \\
\hline C & BTC-4, 4 -ODA & 0.986 & 1.35 & 282 & 5.21 \\
\hline
\end{tabular}

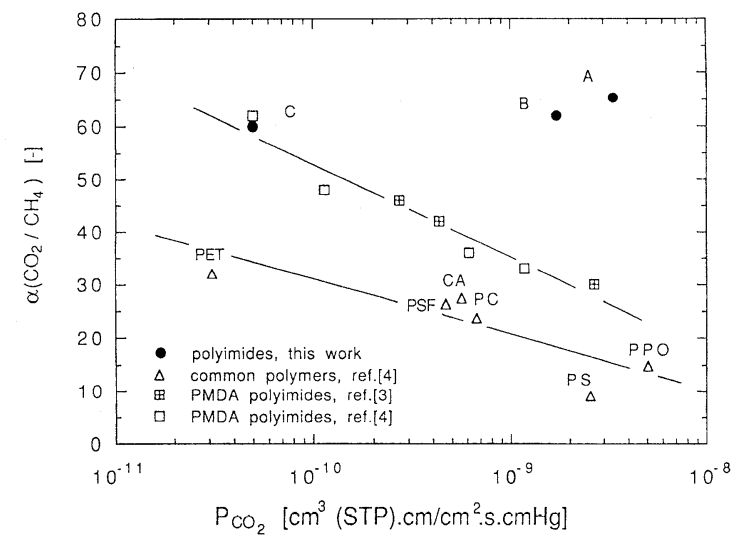

Fig. 2. The relationship between ideal separation factor and mean permeability coefficient for polymers

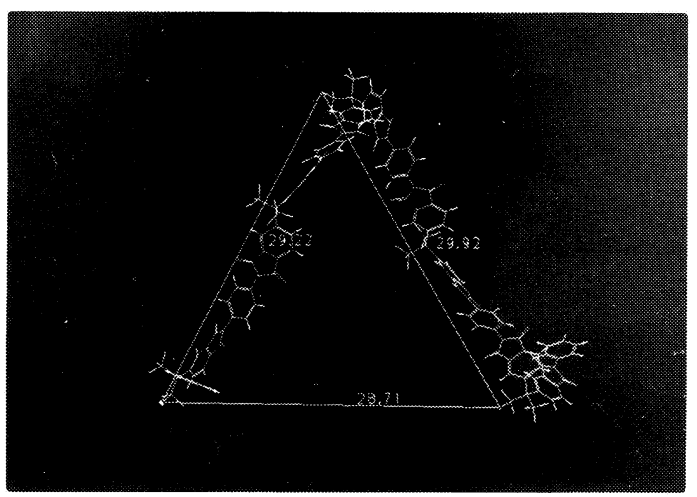

Fig. 4. Computer calculated structure of 6 FDA-p-PDA

tion of the polymers, and the highest density and the smallest $d$-spacing means low packing restriction and results in lowest permeability ${ }^{15)}$. In the present work, 6FDA polyimides show both larger $d$-spacing and higher density as compared to BTC polyimide. 6FDA-p-PDA has higher permeability

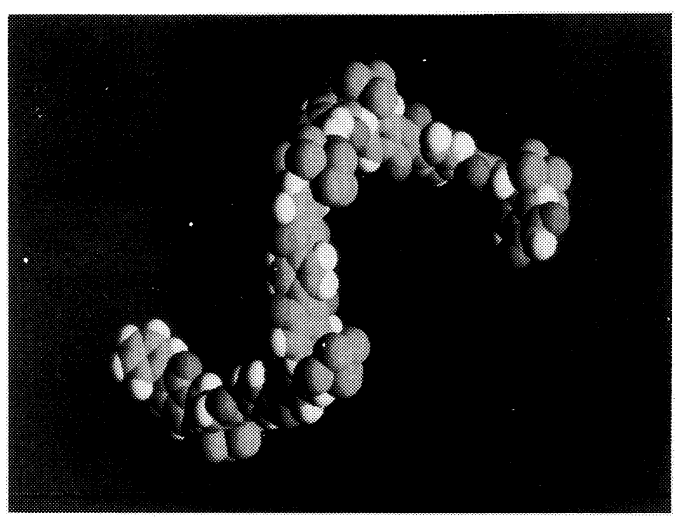

Fig. 3. Space-filling models of 6FDA-p-PDA

than $6 \mathrm{FDA}-4,4^{\prime}-\mathrm{ODA}$ in spite of having higher density and lower $d$-spacing. Presumably, packing situation especially intramolecular polymer structure reflects the gas permeability. We used computer calculation to identify polymer chain structure. Computer simulation results are the followings and figures are shown in Fig. 3 Fig. 19.

\section{Structure of 6FDA-p-PDA}

As shown in Fig. 3, 6FDA-p-PDA polyimide shows helix configuration due to bending and twisting of polymer chain at carbon atom having-C $\left(\mathrm{CF}_{3}\right)_{2}$-substituent groups. The direction of polymer chain is changed at- $\mathrm{C}\left(\mathrm{CF}_{3}\right)_{2}-$ group and repeat unit of helix consists of 4.5 monomer units. One monomer unit has one diamine part and one dianhydride part (Fig. 4). Diameter of helix is around $23 \AA$ and repeating length is around $30 \AA$. Long chain of polymer with 942 atoms are calculated and shown in Fig. 5. Regularity of helix con- 


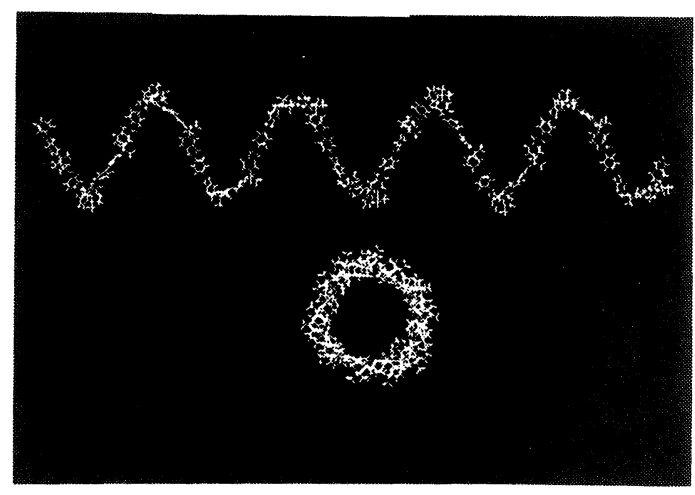

Fig. 5. Polymer-chain structur of 6 FDA-pPDA

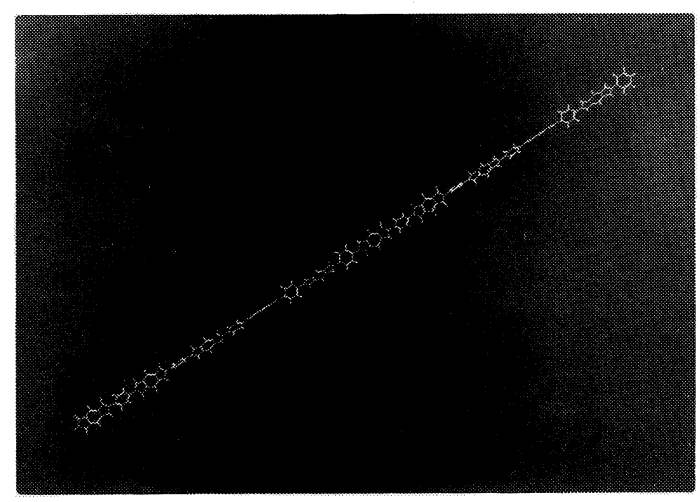

Fig. 7. Computer calculated structure of PM DA-p-PDA

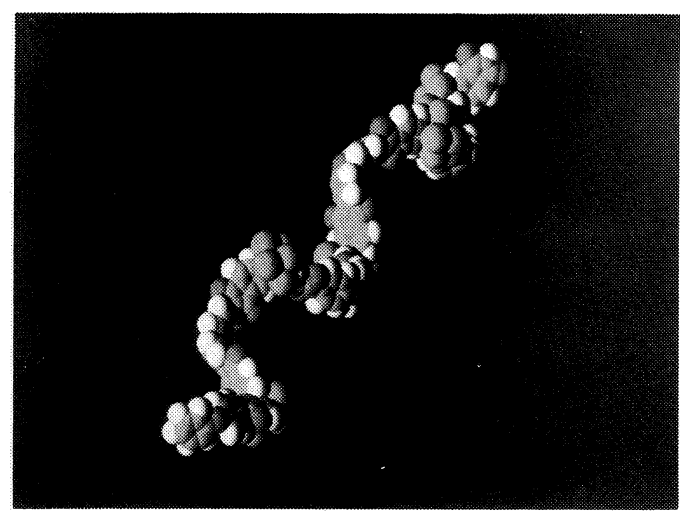

Fig. 9. Space-filling model of 6 FDA-4, 4'ODA

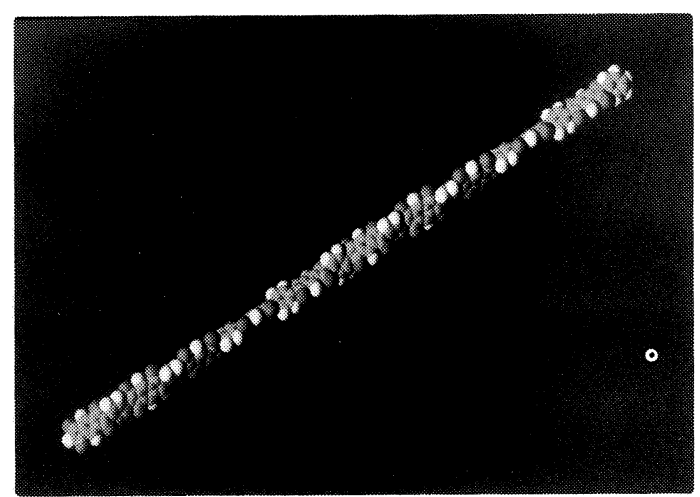

Fig. 6. Space-filling model of PMDA-p-PDA

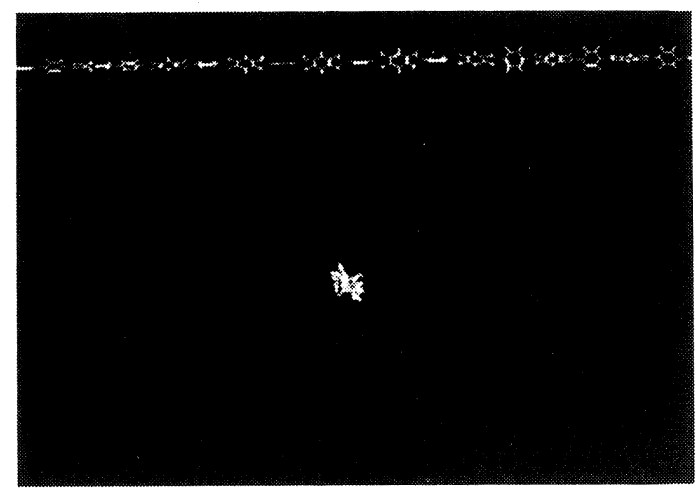

Fig. 8. Polymer chain structure of PMDAp-PDA

figuration is found. Figure of helix from a vertical sectional view is also shown in Fig. 5. Vacant space exist inside of helix.

The structure of PMDA-p-PDA is calculated for comparison. Pyromellitic dianhydride PMDA is used in stead of 6FDA. As shown in Fig. 6, completely straight configuration is found (Fig. 7). There is no vacant space inside of polymer chain (Fig. 8).

\section{Structure of $6 \mathrm{FDA}-4,4^{\prime}-\mathrm{ODA}$}

6FDA-4,4'-ODA also shows helix configuration like 6FDA-p-PDA (Fig. 9). Polymer chain is bent and twisted at carbon atom having-C $\left(\mathrm{CF}_{3}\right)_{2}$-substituent groups. The difference between 6FDA-4, $4^{\prime}-\mathrm{ODA}$ and $6 \mathrm{FDA}-\mathrm{p}-\mathrm{PDA}$ is the repeating length 


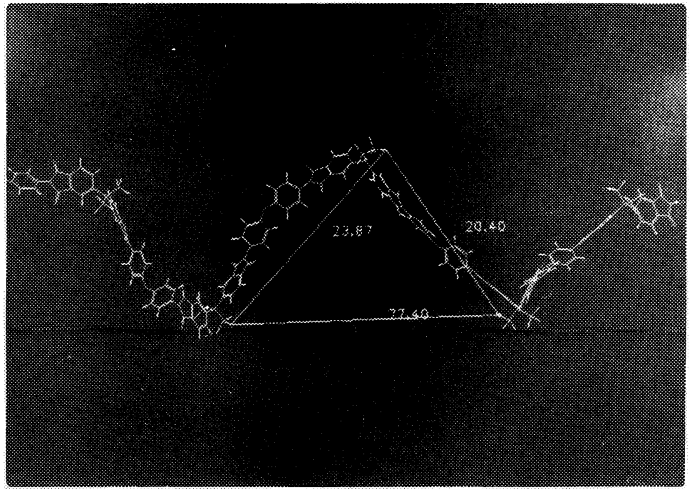

Fig. 10. Computer calculated structure of 6 FDA-4, 4'-ODA

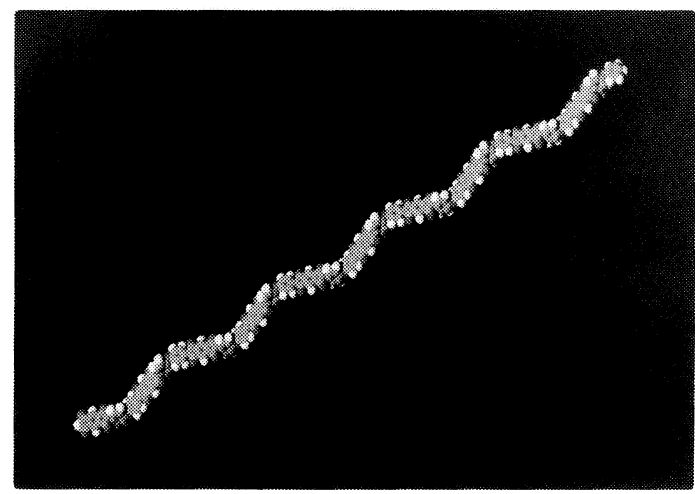

Fig. 12. Space-filling model of PMDA-4, 4'ODA

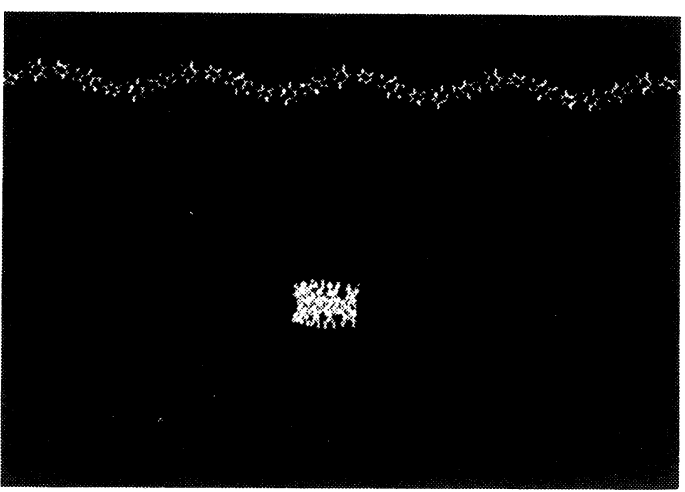

Fig. 14. Polymer chain structure of PMDA$4,4^{\prime}$-ODA

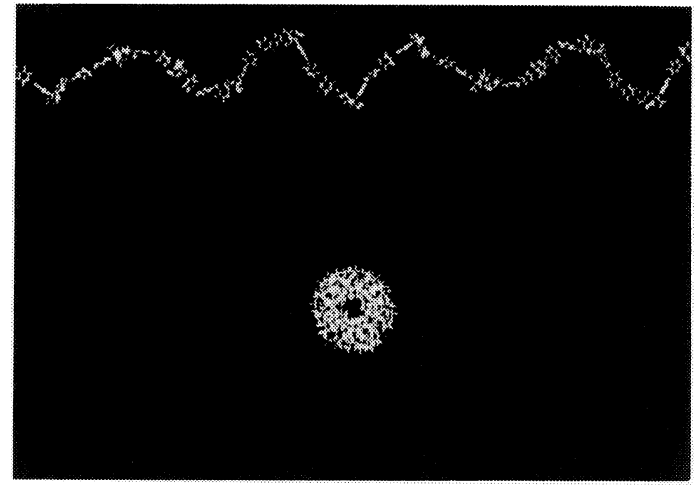

Fig. 11. Polymer chain structure of 6 FDA4, 4'-ODA

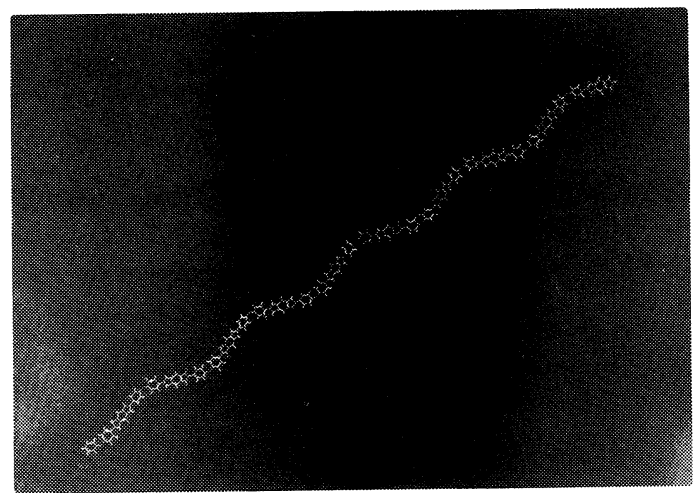

Fig. 13. Computer calculated structure of PM DA- 4, 4'-ODA

as shown in Fig. 10. The direction of polymer chain is changed at one monomer unit and repeat unit of helix consists of 2 monomer units. Repeating length of helix is $20.40 \AA$ and $23.87 \AA$. Helix structure is irregular as compared to 6FDA-p-PDA.

Long chain structure of polymer with 1162 atom is shown in Fig. 11, and helix configuration has small vacant space inside as compared to $6 \mathrm{FDA}-$ $\mathrm{p}-\mathrm{PDA}$. This is one reason that 6FDA-p-PDA gives higher permeability than $6 \mathrm{FDA}-4,4^{\prime}-\mathrm{ODA}$ due to having larger free volume.

The structure of PMDA-4,4'-ODA is calculated for comparison and shown in Fig. 12. Polymer chain shows zigzag structure, and helix configuration is not found (Fig. 13). Figure of polymer 


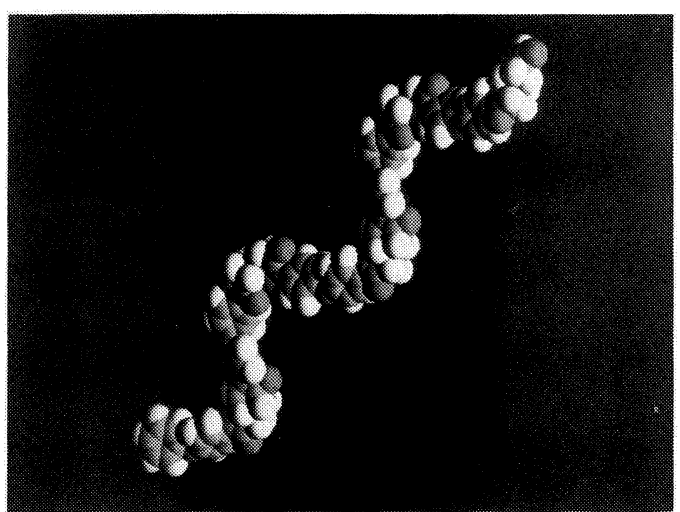

Fig. 15. Space-filling model of BTC-4, 4'ODA

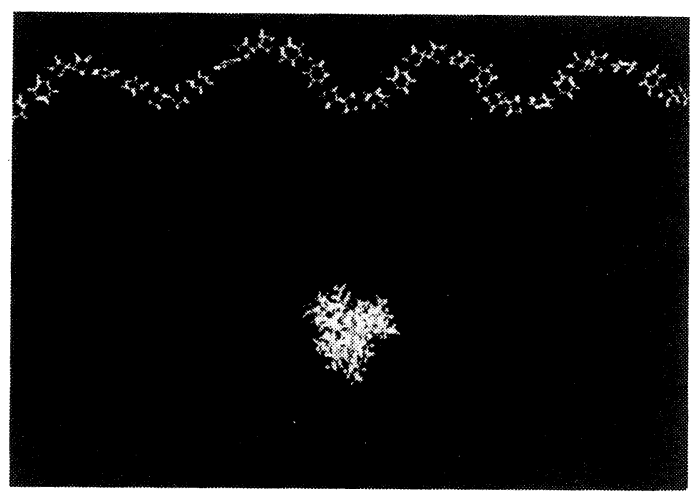

Fig. 17. Polymer chain structure of BTC-4, $4^{\prime}-$ ODA

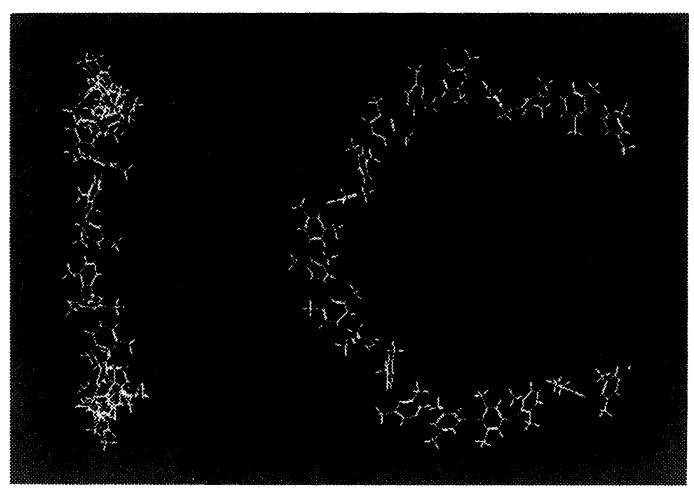

Fig. 19. Polymer chain structure of PPO

from a vertical sectional view (Fig. 14) shows no vacant space inside of the polymer chain.

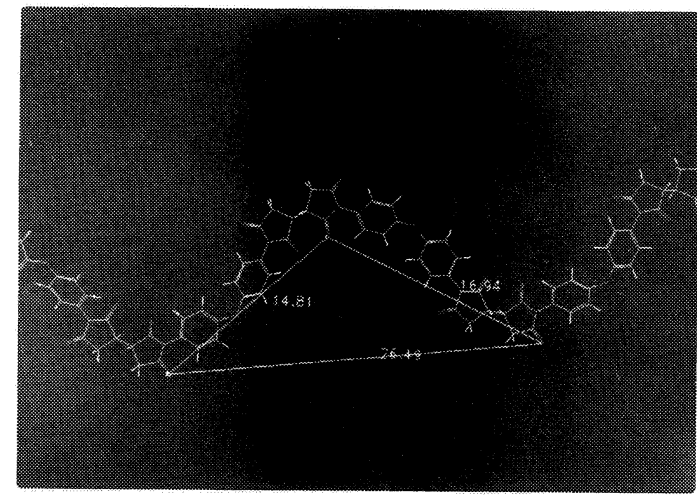

Fig. 16. Computer calculated structure of BTC-4, 4'-ODA

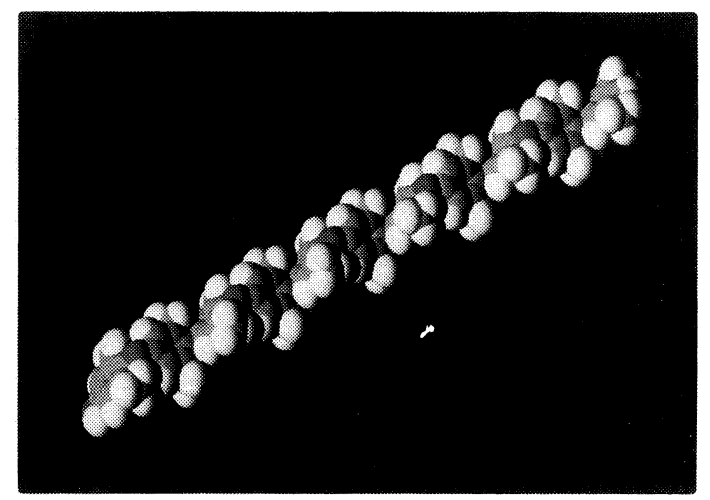

Fig. 18. Space-filling model of PPO

\section{Structure of BTC-4, $4^{\prime}-\mathrm{ODA}$}

BTC-4, $4^{\prime}$-ODA polyimide structure is shown in Fig. 15 as a sample of polymer which provide high selectivity but low permeability. Zigzag structure is found but no helix configuration is observed (Fig. 16).

Long chain of polymer with 822 atoms are calculated and shown in Fig. 17. Polymer structure doesn't have vacant space inside of the polymer chain. Presumably, zigzag structure contribute separation of free volume of the polymer and selectivity is increased but no apparent contribution to permeanility increase.

The structure of poly (phenylene oxide) (PPO) is shown in Fig. 18 for comparison. PPO provides high permeability but low selectivity. Polymer 
structure is flexible because main chain consist of ether bond. Polymer chain can rotate at - $\mathrm{O}-$ bond. There doesn't show helix configuration (Fig. 19). Flexibility of the polymer chain can contribute to high permeability of the polymer.

As discussed above, helix configuration is the characteristic of 6 FDA polyimide. Helix configuration can be one of the important reason for high selectivity and high permeability of hexafluorosubstituted polyimides. Helix configuration can contribute the increase of free volume in the polymer and control the diffusivity of penetrant gas molecules by separating free volume. On the other hand, straight configuration can be easily packed so that free volume decreases. High permeation polymer like PPO which has high flexibility can easily provide large size free volume which occur high permeability and low selectivity.

\section{CONCLUSIONS}

6FDA polyimides exhibit both a higher gas selectivity and permeability than presently available polymers. Computer calculation shows 6FDA polyimides have helix configuration due to bonding and twisting of polymer chain at carbon atom having $-\mathrm{C}\left(\mathrm{CF}_{3}\right)_{2}$ - substituent groups. Helix configuration cannot be found in other polymers such as BTC-4,4'-ODA, PMDA-p-PDA, PMDA-4,4'-ODA and PPO. So, helix configuration is the characteristic of 6 FDA polyimide and can be one of the im- portant reason for high selectivity and high permeability.

\section{REFERENCES}

1) T. H. Kim, W. J. Koros, C. R. Husk, and K. C. O'Brien : J. Membrane. Sci., 37, 45 (1988).

2) S. A. Stern, Y. Mi, and H. Yamamoto : J. Polym. Sci. : Part B : Polym. phys., 27, 1887 (1989).

3) S. A. Stern, R. Vaidyanathan : J. Membrane. Sci. 49, 1 (1990).

4) M. R. Coleman, W. J. Koros : J. Membrane. Sci., 50, 285 (1990).

5) K. Tanaka, H. Kita, K. Okamoto : Senigakkaisi, 46, 541 (1990).

6) J. H. Petropoulos : J. Membrane. Sci., 53, 229 (1990)

7) T. Nakagawa, T. Nishimura, T. Ishiguro, and A. Higuchi : Polym. Preprints Jpn. : 40, 2323 (1991)

8) K. Toi, H, Suzuki, T. Ito, I. Ikemoto, and T. Kasai : Polym. Preprints Jpn., 40, 3401 (1991)

9) K. Okamoto, H. Kita: kobnsikako, 41, 16 (1992).

10) K. Matsumoto and P. Xu. : J. Appl. Polym. Sci., in press.

11) K. Matsumoto and P. Xu. : J. Membrane. Sci., to be received.

12) R. J. Roe, Edited "Computer Simulation of Polymers" Prentice-Hall, New Jersey, 1990.

13) A. S. Argon : Polym. Prep. 31, 689 (1990).

14) H. Takeuchi and K. Okazaki : J. Chem. Phys., 92, 5643 (1990) ; H. Takeuchi : ibid, 93, 2062 (1990) ; 93, 4490 (1990); H. Takeuchi, R. J. Roe and J. E. Mark : ibid, 93, 9042 (1990).

15) S. L. Mayo, B. D. Olafson, W. A. Goddard III : J. Phys. Chem., 94, 8897 (1990).

（受付 1992 年 3 月 19 日） 